\title{
Sistemas Judiciales: Bases para su Reivindicación ${ }^{(*)}$
}

Roberto Omar Berizonce

Profesor de Derecho Procesal en la Universidad Nacional de La Plata, Argentina.

Presidente Honorario del Instituto Iberoamericano de Derecho Procesal.

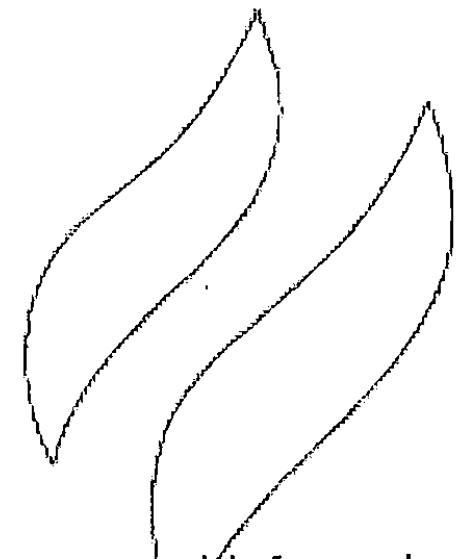

Álvaro J. Perez Ragone

Doctor en Derecho en la Universidad de Colonia. Profesor de Derecho Procesal Escuela de Derecho de la Pontificia Universidad Católica de Valparaíso.

n los últimos meses dél año pasado y, cómo no, en los primeros del presente año, se han configurado diversos sucesos de conocimiento público que han puesto nuevamente sobre el debate-mediático.la.eficiencia-y-utilidad que tiene tanto el Sistema Judicial Peruano, como la idoneidad de sus principales operadores; es decir, Jueces y Vocales.

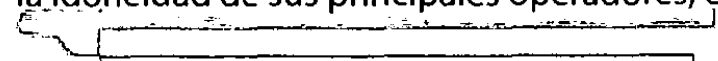

Eventos como la encarcelación (y posterior liberación) de Magaly Medina y el escándalo de los petróaudios en el-2008; asícomo la-Śentencia de primera instancia en el proceso penal seguido cóntra el ex presidente Alberto Fujimori y la absolución de presuntos culpables por diversos delitos al interior del país en el 2009, han desencàdenados que los medios de comunicación masiva (a través de su "especializada" opinión) opinen y publiquen opiniones sobre la viabilidad de nuestro Podèr Judicial.
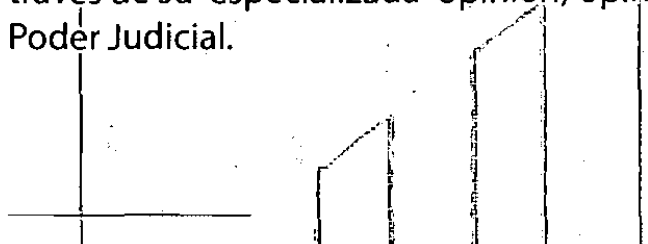

(*) La presente entrevista fue elaborada por Martín Chocano Tabja, alumno del Décimo Ciclo de la Facultad de Derecho dé la Univérsidad de Lima y Miembro de la Comisión de Edición de la Revista ADVOCATUS. Asimismo, ADVOCATUS agradece especialmente al Dr. Adrián Simons Pino, Miembro del Consejo Consultivo de ADVOCATUS, por su ayuda en la elaboración de la presente entrevista. 
En ese sentido, ADVOCATUS entiende que la reforma y evaluación del servicio de justicia debe estar en permanente agenda nacional y no solo en momento que algún personaje conocido le toca evidenciar las "fallas" $y$ "virtudes" del mismo. Es por ello, que para la presente Edición de Aniversario hemos invitado a dos de los más renombrados especialistas en reforma judicial de Latinoamérica como los son el doctor Roberto Omar Berizonce y el doctor Álvaro Pérez Ragone, para que sobre la base de su autorizada opinión y experiencia compartan con la comunidad juridica peruana algunos puntos esenciales que consideran claves para que un Sistema Judicial pueda ser eficiente.

Lejos de evaluar los mismos sobre la base de conductoras de televisión, escándalos políticos, ideologías y sentencias particulares, los especialistas antes señalados han tenido la gentileza para con nuestra Asociación de responder este breve cuestionario, el que de ninguna manera pretende siquiera empezar a agotar los temas para un reforma de justicia, sino meramente plantear ciertos puntos necesarios para ella.

\section{¿Existe en su pais un adecuado sistema de justicia?}

Roberto Omar Berizonce (ROB): La evaluación acerca de si un sistema de justicia funciona de modo adecuado, remite a la consideración al menos de tres indicadores generalmente utilizados como marco de referencia al respecto: 1 ) la duración de los procesos; 2) los costos para el justiciable en términos de acceso a la justicia; y 3) el valor intrínseco de las sentencias, que exteriorizan los resultados de la función jurisdiccional. En atención a ello, puede afirmarse fundadamente que el sistema de justicia no funciona adecuadamente en Argentina.

Álvaro Pérez Ragone (APR): Me pronunciaré solo por Chile. No puede darse una respuesta que englobe a todo el sistema de Justicia. De los tres pilares básicos para el funcionamiento de un sistema: recursos humanos e infraestructura, estructura y funcionamiento orgánico, proceso las respuestas varían según se hable de la justicia penal (en mi criterio sobresaliente en las tres áreas), de la justicia civil (deficiente en las tres áreas, pero sin problemas de corrupción o corruptela y en un franco proceso de modernización); la justicia de familia (bien pensada en las tres áreas, pero pésimamente implementada, aunque con medidas tendientes a mejorar el sistema, por cierto de moderno proceso y cambio radical orgánico en la primera instancia); para la justicia laboral vale lo mismo que para la de familia.

El sistema judicial está fuertemente jerarquizado y con ciertos límites no claros a la independencia interna del poder judicial, es decir tribunales superiores muy conservadores vs. Tribunales inferiores innovadores.

La Justicia Constitucional se desarrolla embrionariamente con un TC y controles de la justicia ordinaria para caso de vulneración de derechos fundamentales.

En conjunto puede una respuesta esperanzadora: el nivel de corrupción es muy bajo comparado con el resto de Latinoamérica, el Sistema de Justicia está en una etapa de reforma radical en todas las áreas, hay conciencia y voluntad de cambio necesario. Los problemas se manifiestan normalmente en la implementación de las reformas.

\section{¿Cuáles consideraria que son los retos de la Administración de Justicia en Ibero América? En ese sentido, cuáles serían las bases para un sistema judicial eficiente.}

ROB: Precisamente, el principal desafío de la justicia de nuestros países está constituido por la necesidad de consensuar políticas públicas para el área y ejecutarlas con continuidad y eficiencia. Se requieren verdaderos Pactos de Estado para el sector judicial, que comprometan la voluntad y los esfuerzos de los tres poderes del Estado. Sin ello, las posturas y criterios erráticos terminarán gobernando, sin destino fructífero, la administración de la justicia. El Pacto de Estado para la justicia debe fijar y asegurar ciertas líneas básicas: independencia de los jueces y del Poder Judicial, organización judicial eficiente que incluye, entre otros, un sistema de designaciones 
objetivo, con participación abierta y basado en las capacidades y méritos de los postulantes, carrera judicial orgánica, acceso irrestricto a la justicia; modelos procesales adecuados.

APR: Los retos principalmente son tres: 1) Desarrollar un propio sistema de justicia importando lo mejor de otras experiencias. Muchos países continúan con fuerte arraigo en la tradición española (siglo XIX) y funcional como orgánicamente anacrónicos y de espaldas al ciudadano; 2) Crear sistemas adecuados de incentivos negativos para desterrar la corrupción en la justicia; 3) Mejorar la gestión judicial en eficiencia.

Las bases no podría desarrollarlas sin pecar de insuficiencia en tan corto espacio. Pero las resumo: transparencia, justicia, publicidad, eficiencia.

\section{En este orden de ideas, ¿Cuáles considera que son las claves para una correcta reforma pro- cesal en Ibero América?}

ROB: La reforma procesal es tan solo uno de los aspectos a considerar, dentro de la política judicial. Existen diversas cuestiones, todas interconectadas, que inciden en el funcionamiento del aparato judicial, sintetizadas por Carnellutti en: a) los hombres (y mujeres) -que conduce a temas como la formación y capacitación de jueces y abogados; sistemas de reclutamiento y designación; carrera profesional; mecanismos de enjuiciamiento, etc.-; b) la dotación material o presupuesto -que supone la asignación de fondos suficientes por parte del Estado; la administración presupuestaria; edificios, nivel de las inversiones en tecnología, sistemas de gestión de las causas, etc.-;c) el modelo procesal-que está condicionado a los elementos anteriores-.

Con esa aclaración, personalmente pienso que la reforma procesal en Iberoamérica debería seguir las pautas del Código Modelo de Proceso Civil para Iberoamérica elaborado y aprobado por el Instituto Iberoamericano de Derecho Procesal en 1988. Sintéticamente: proceso de conocimiento por audiencias (preliminar y vista de causa); ampliación de poderes-deberes del juez; régimen recursivo simplificado, etc.
Con el agregado de un régimen específico de tutelas urgentes para los derechos de atención preferente, en consonancia con los derechos fundamentales que se derivan de la Constitución y de los pactos internacionales sobre derechos humanos. Asimismo, incorporación de estructuras monitorias y, en general, técnicas de simplificación de los procesos.

APR: Algunas claves son comenzar a mirar a Europa (Francia-Alemania-Reino Unido) y el desarrollo de un proceso civil europeo con armonía y considerando las bases enunciadas supra 2.

En su experiencia, considera que los sistemas de designación de jueces vigentes son los ideales ¿En su opinión cuál sería el mejor sistema para estos efectos?

ROB: No existen sistemas ideales para la designación de los jueces. Hay tan solo modelos teóricos que deben ser confrontados con la realidad de su aplicación. Un primer problema se presenta con la adopción de sistemas ajenos a la idiosincrasia y a la experiencia propia, o la mixtura de elementos provenientes de uno y otro. Ello ha conducido a menudo a experiencias fallidas. El otro problema es el de la desnaturalización del sistema establecido, que queda falseado en sus resultados. Es lo que ha acaecido en la experiencia argentina reciente. La reforma constitucional de 1994 creó el Consejo de la Magistratura del Poder Judicial de la Nación, integrado periódicamente de modo que se procure el equilibrio entre la representación de los órganos políticos resultantes de la elección popular, de los jueces de todas las instancias y de los abogados de la matrícula federal; lo integran también otras personas del ámbito académico y científico, en el número y la forma que indique la ley (artículo 114, Constitución Nacional). Sin embargo, las leyes reglamentarias terminaron desnaturalizando el. texto constitucional quebrando el equilibrio al asignar preponderancia a los representantes de los órganos políticos.

En definitiva, todos los sistemas tienden a asegurar el acceso de los mejores aspirantes y su selección en base a capacidades y méri-

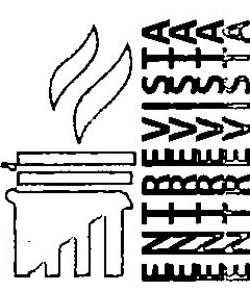


tos objetivos, pero sin embargo las bondades en concreto solo pueden apreciarse en tanto esos objetivos se cumplen sin distorsiones. $\mathrm{Ni}$ manejo por los sectores político-partidista, ni cooptación por los propios jueces superiores.

APR: No podría emitir un juicio general. Creo que el sistema ideal no existe. Sí lo acercable a lo ideal para tener el mejor recurso humano, que acceda en forma justa y equitativa con una base de legitimidad y participación mínima de los otros poderes del Estado.

\section{¿Cuál es su impresión respecto del Código Modelo de Cooperación Interjurisdiccional para Latinoamérica que fue materia de pre- sentación en el último Congreso Iberoameri- cano realizado en Lima? ¿Considera que será una herramienta útil para la administración judicial?}

ROB: El Código Modelo de Cooperación Interjurisdiccional para Iberoamérica, obra del Instituto Iberoamericano de Derecho Procesal, constituye un punto de referencia obligado para la reforma y actualización de las legislaciones nacionales, consagrando las más evolucionadas instituciones del derecho internacional privado en el relevante ámbito de la cooperación interjurisdiccional. Debemos confiar en que nuestros países adopten sus principios, sin perjuicio de las regulaciones por vía de tratados o convenciones entre los Estados.

APR: Es una herramienta útil y necesaria. Precisamente seguir el modelo de paulatino acercamiento a la armonización. Sí soy escéptico que todos los países de Latinoamérica pueden si quiera comenzar intentar implementarlo. Muchos países están aún con reformas internas urgentes. Otro desorientados.

Dentro de su experiencia respecto a los órganos de control concentrado de la Constitución (ya sean Cortes Constitucionales o Cortes Supremas) considera que su actuación esta correctamente delimitada. ¿Cuáles en su opinión deben ser los límites de actuación de estos órganos?
ROB: La función de los órganos de control concentrado de la constitucionalidad (y de la "convencionalidad", en alusión a la observancia de los pactos y convenciones internacionales sobre derechos humanos en general), de las normas infraconstitucionales y aún de los actos de los demás poderes del Estado, está necesariamente limitada y condicionada en todos los sistemas-Cortes Supremas, Tribunales Constitucionales-. El problema central radica en la búsqueda y logro del necesario equilibrio entre las atribuciones asumidas por los jueces y el ámbito reservado por la propia Constitución al ejercicio de los poderes políticos. Sin caer en un criticable "gobierno de los jueces", para el cual no están preparados ni tienen potestades asignadas en ningún modelo, el Poder Judicial y dentro de él los Superiores Tribunales, son parte-y por cierto, significativa- del gobierno. A ellos les está asignado el control de los actos legislativos y administrativos con el objetivo prioritario de asegurar la virtualidad y efectividad de los derechos y garantías reconocidas en la Constitución a todos los ciudadanos, cuando aquellos aparecen violados o menoscabados. Los límites y fronteras son necesariamente difusos, pero la búsqueda del equilibrio, que supone la no intromisión en el ejercicio de atribuciones propias y excluyentes de los restantes poderes, está en manos de los propios magistrados-son de origen pretoriano las clásicas doctrinas de las politicals cuestions y del self restraint, como otras recientes de la "gravedad institucional" o de la "relevancia" de las cuestiones-, quienes están "forzados" a encontrar aquel punto de equilibrio. De lo contrario, el enjuiciamiento político quedará habilitado para asegurar el cheqs and balances. En una república no hay poder sin control, y ello vale recíprocamente para los tres poderes.

APR: No es posible dar una respuesta única. $\mathrm{Si}$ me pregunta cuáles sentencias de TC realmente son un placer leerlas, debo contestar las de Colombia. Los sistemas de control de constitucionalidad en Latinoamérica son tan variados que en la pregunta se obvio considerar el supuesto donde exitan simultaneamente CS y TC. Creo que ese es el sistema óptimo. No creo en la fijación detallada de la limitación para uno o para 
el otro en lo que a control de constitucionalidad se refiere. El enfrentamiento entre ambos creo coadyuva al control y blance de poderes.

\section{Es en su opinión, la dificultad del acceso a la justicia constituye un problema gravitante, ¿Cómo podría solucionarse este problema?}

ROB: Las barreras sean de tipo económico o culturales constituyen sin dudas graves obstáculos al acceso a la justicia. La remoción o mitigación de las desigualdades de base económica o sociocultural es misión del Estado en general, del gobierno que integra también el Poder Judicial. Los mecanismos tradicionales se fundaban en razones puramente caritativas y llevaron a establecer la carta de pobreza e instituciones similares que, no obstante su remozamiento, en general se han mostrado insuficientes. Los altos costos del proceso siguen estando fuera del alcance de los grupos o sectores más desfavorecidos. En la legislación europea, ya desde mediados del siglo $\mathrm{XX}$, se generalizaron los sistemas de cobertura social jurídica (Inglaterra, Francia, Alemania), que sin embargo no han sido organizados en Iberoamérica donde se ha persistido en soluciones parciales (carta de pobreza, beneficio de litigar sin gastos). Sin embargo, en los años recientes la admisión de la tutela de los derechos colectivos, con legitimaciones extraordinarias-Defensor del Pueblo, asociaciones- $y$ en conexión con los efectos erga omnes de la sentencia, ha venido a paliar el problema al menos en sectores de la tutela de consumidores y usuarios y del medio ambiente en general.

APR: Muy gravitante. La solución es mayor apoyo financiero y capacitación de quienes deben estar cerca de los que cultural, económica o socialmente se encuentran impedidos o limitados en acceder a la justicia.

\section{¿Cómo debe ser gobernado el Poder Judicial, en manos de quién y cuántos? ¿Cómo enfren- tar el problema de la corruptela en las Cortes? ¿Hay solución para ello?}

ROB: El gobierno del Poder Judicial plantea cuestiones complejas que se relacionan prin- cipalmente con: 1. La administración económica-financiera de los recursos asignados por el Congreso, y la ejecución presupuestaria; 2 . El ejercicio de las potestades disciplinarias sobre magistrados, funcionarios y personal subalterno; 3. La participación en el procedimiento constitucional de remoción de los magistrados; 4. El dictado de los reglamentos relacionados con la organización judicial, en general. El debate gira habitualmente en torno a cuáles de esas potestades se asignan a un órgano plural con participación equilibrada de los diversos sectores, incluyendo al de los propios magistrados; y cuáles se reservan al Tribunal Supremo. Las experiencias han sido diversas; en Argentina, la reforma constitucional de 1994 trasladó algunas potestades que pertenecían hasta entonces a la Corte Suprema Nacional (CSN) y las adjudicó al Consejo de la Magistratura. Ello motivó fricciones en los primeros tiempos, que aun persisten en punto al manejo de la administración financiera; en ese terreno, la CSN confronta también de modo permanente con el Poder Ejecutivo Nacional (PEN) por la transferencia de partidas presupuestarias. En conclusión, si bien en teoría la creación del Consejo de la Magistratura, "democratizó" en ciertos aspectos el gobierno del Poder Judicial, generó por otro lado numerosos conflictos por la puja entre los diversos actores. Por último, y no menos importante, las leyes del Congreso que reglamentaron el texto constitucional terminaron desnaturalizando la composición del Consejo, al quebrar el equilibrio entre los distintos segmentos que lo integran, cuando asignó prevalencia a los representantes de los poderes políticos en desmedro de los restantes. Todo lo cual, al presente, ha generado una lógica desconfianza por la amenaza a la independencia de los jueces, particularmente por la presión que se ejercer a través del procedimiento de remoción.

La otra cara del problema está constituida por los actos de corrupción que pueden endilgarse a algunos magistrados. Son situaciones excepcionales en Argentina, que afectan a ciertos fueros que, sin embargo, resultan preocupantes $y$ en relación a los cuales debería operar el enjuicia-

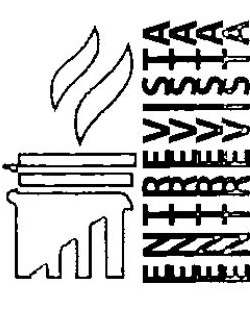

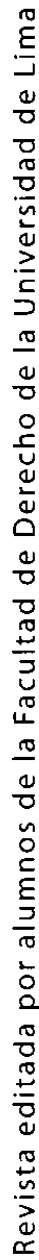

$\frac{9}{5}$ 
miento político, bajo reglas claras, sin perjuicio de los controles disciplinarios preventivos.

APR: Creo que la combinación de control interno y auditoría externa (estructura empresarial de mercado simplemente) puede ser un buen inicio. No creo que todos los sistemas judiciales estén en el mismo nivel de corruptela, por ello las soluciones son más que variadas.

Los cambios culturales pueden ser anteriores o posteriores a los estructurales, políticos o profesionales. No me atrevo a dar una respuesta única para Latinoamérica.

\section{¿Cuál debe ser el rol del Juez Civil en el proceso y en la sociedad? Asimismo, ¿cuál considera usted, que debe ser el rol del abogado litigante en la sociedad?}

ROB: El juez es el protagonista principal del proceso civil contemporáneo, por el considerable aumento de sus poderes-deberes, especialmente cuando están en juego derechos fundamentales de tutela preferente-derechos "personalísimos"-, de menores e incapaces, de incidencia colectiva, consumidores y usuarios, medioambiente, derechos sociales en general. Sin perjuicio, naturalmente, que se reserve a las partes la iniciativa y disponibilidad del derecho material, con correlato como verdadero "motor" en el terreno de la instrucción probatoria. $\mathrm{El}$ proceso civil constituye una labor conjunta que realizan en común las partes (y sus abogados) y el juez, a quien corresponde la dirección -juez director, con poderes de ordenación y de instrucción-. Ahora bien, del adecuado manejo del instrumento procesal por el juez depende generalmente la correcta instrucción de la causa y el esclarecimiento de la verdad de los hechos controvertidos, lo cual resulta esencial para el acierto y la justicia intrínseca de la decisión, que es el fin del proceso. La posición "activa" del juez respecto de las pruebas no es incompatible con su imparcialidad, que no le impide querer que su sentencia sea justa.

Precisamente, el rol que la sociedad espera que el juez -la jurisdicción, en general-cumpla no es otro que el de funcionario público llamado a dispensar la justicia en los casos concretos. Y para satisfacerlo debe estar en claro respecto de los hechos que se debaten y aplicar el derecho interpretándolo del modo más adecuado a la tutela efectiva y concreta de los derechos fundamentales en juego.

El abogado, a su vez, debe servir eficazmente a la justicia, como uno de sus más preciados colaboradores. No solo a través de su actuación en juicio, sino también cuando participa en la búsqueda de soluciones autocompuestas. Su deber profesional le impone consagrarse enteramente a la defensa de los derechos de su cliente, sin embargo no puede serle ajeno el interés general comunitario comprometido en la eficaz y rápida realización de justicia. La misión del abogado, por tanto, consiste en esencia en coadyuvar y contribuir al logro de la justicia, finalidad pública del servicio. Ello supone que le corresponde asumir singulares funciones de igualación de las partes en el proceso, de depuración, simplificación y desformalización del proceso, de esclarecimiento de las circunstancias objeto de debate, de aceleración de los tiempos procesales y, sobre manera, asumir en plenitud los deberes de lealtad, probidad y buena fe para con el juez y con las partes.

APR: El juez debe tener un rol activo en el proceso civil de conocimiento, casi nulo en el de ejecución con tareas delegables y ganarse por sus sentencias en la justificación de las mismas la legitimidad y apoyo de la sociedad y de las pares aún en discordia. Pero el juez debe ser juez, no es presidente, jefe de gabinete o parlamentario.

El abogado litigante debiera cumplir un rol de excelencia y de servicio a la administración de justicia. Creo en la selección (exámenes) para permitir el acceso al mercado de los mejores según mínimos estándares. Los mercados están saturados y el entorno de posibilidad de ejercicio sobre límites legales o éticos favorecidos.

Recientemente se ha ocasionado un escándalo político-mediático en nuestro País conocido 
como el Petro-Gate. Este problema radica en que mediante grabaciones obtenidas a través de un espionaje telefónico, realizado sin autorización alguna, se descubrieron indicios sobre un supuesto ilícito que involucra a gente de las más altas esferas del gobierno. En su opinión, ¿dichas grabaciones pueden ser aportadas como medios de prueba en un proceso judicial?

ROB: Por un principio elemental de derecho, las pruebas asumidas ilegalmente son nulas de nulidad absoluta, por lo que no pueden ser utilizadas como evidencia en el proceso judicial, cualesquiera fueren las circunstancias.

APR: Si la pregunta se refiere a un proceso judicial penal, sometería a examen la prueba que ronda la obtención ilícita o injusta.

Si estamos hablando de un proceso administrativo (contencioso administrativo), civil o constitucional, dejaría libre la ponderación judicial sobre la admisibilidad y/o ponderación de esa prueba. Quizás termine siendo desvirtuada por otra o quizás, más grave, sea la única prueba existente. 